\title{
Specific PCR detection of Peptostreptococcus magnus
}

\author{
M. P. Riggio and A. Lennon \\ Infection and Immunity Research Group, University of Glasgow Dental School, 378 Sauchiehall Street, \\ Glasgow G2 3JZ, UK
}

Correspondence

M. P. Riggio

m.riggio@dental.gla.ac.uk

\begin{abstract}
Peptostreptococcus magnus is the most pathogenic and one of the most common Gram-positive anaerobic cocci found in human clinical specimens. The organism has been isolated in pure culture from a range of serious infections, including meningitis and endocarditis. However, isolation of Peptostreptococcus magnus from the oral cavity has rarely been attempted. Identification of Peptostreptococcus magnus in clinical specimens is reliant upon microbiological culture and biochemical methods, which often give ambiguous results. The aim of this study was to develop a PCR assay for the specific detection of Peptostreptococcus magnus in oral clinical specimens. PCR primers specific for Peptostreptococcus magnus DNA were derived by comparison of 16S rRNA gene sequences and selection of primers that demonstrated specificity at their $3^{\prime}$ ends for Peptostreptococcus magnus. PCR positivity for Peptostreptococcus magnus DNA was indicated by the amplification of a 553 bp product. The PCR assay was then used to attempt detection of Peptostreptococcus magnus DNA in subgingival plaque samples from adult periodontitis patients and pus aspirates from subjects with acute dento-alveolar abscesses. The PCR assay was demonstrated to be highly specific for Peptostreptococcus magnus DNA, since no PCR products were obtained when genomic DNA from a wide range of other oral bacteria, including closely related Peptostreptococcus species, was used in the PCR assay. Confirmation of specific amplification of Peptostreptococcus magnus DNA was obtained by digestion of PCR products with the restriction endonuclease Rsal, which gives a unique restriction profile for Peptostreptococcus magnus. Of the 33 subgingival plaque samples analysed, 2 (6\%) were positive for Peptostreptococcus magnus DNA. None of the 60 pus aspirates analysed was positive for Peptostreptococcus magnus DNA. It is concluded that Peptostreptococcus magnus is not a major pathogen in adult periodontitis or dentoalveolar abscesses. The PCR assay provides a more rapid, specific and sensitive alternative to conventional methods for identification of Peptostreptococcus magnus in clinical specimens.
\end{abstract}

Received 24 June 2002

Accepted 12 December 2002

\section{INTRODUCTION}

Peptostreptococcus magnus is a Gram-positive anaerobic coccus (GPAC) and is the most pathogenic and one of the most frequently isolated GPAC species found in human clinical specimens. Peptostreptococcus magnus is regarded as part of the normal flora of the skin, urogenital tract and prepubertal vaginal flora (Murdoch, 1998) and has been isolated from a wide variety of body sites in pure culture. These include cases of endocarditis (van der Vorm et al., 2000), meningitis (Brown et al., 1994) and pneumonia (Panagou et al., 1991), some of which have been fatal. Peptostreptococcus magnus is most commonly associated with infection of skin and soft tissue and bone and joint infections (Bourgault et al., 1980), but has also been isolated from cases of septic arthritis following prosthetic joint replacement (Fitzgerald et al., 1982), prosthetic implant

Abbreviation: GPAC, Gram-positive anaerobic coccus. infections (Davies et al., 1988), breast abscesses (Edmiston et al., 1990), diabetic foot infections (Johnson et al., 1995) and upper respiratory tract infections such as sinusitis and otitis media (Brook, 1994; Murdoch et al., 1994). Peptostreptococcus magnus was recently isolated from the subgingival plaque of children with primary dentition (Kamma et al., 2000), and this represents the first report to date of Peptostreptococcus magnus isolation from the oral cavity. However, it has been observed that other GPAC species are more commonly found in infections of the central nervous system, abdomen, female genitourinary tract and the mouth (Brook, 1988, 1994; Murdoch et al., 1994).

The identification of Peptostreptococcus magnus in clinical samples has been particularly problematic, most notably because of the difficulty in differentiating it from Peptostreptococcus micros. This has been attempted primarily by using conventional bacterial culture in combination with biochemical tests. Initial tests used, such as colony morph- 
ology, alkaline phosphatase production and carbohydrate fermentation profiles, have proved inadequate for identification of Peptostreptococcus magnus and, indeed, other GPAC species, often giving rise to ambiguous results (Murdoch, 1998). Identification of GPAC species by assessment of their proteolytic activities using pre-formed enzyme kits has been more favourable, differentiating extremely well between Peptostreptococcus magnus and Peptostreptococcus micros (Murdoch, 1998). Gas-liquid chromatography (GLC) has been used to detect volatile fatty acid production by GPAC species and thus classify them into three groups based on the volatile fatty acids produced (Murdoch, 1998). However, this is a time-consuming and costly procedure that is beyond the capabilities of most diagnostic laboratories.

The aim of the current study was to develop a more reliable, specific and rapid alternative to those methods used previously for identification of Peptostreptococcus magnus in clinical specimens. A PCR assay was developed using a primer pair targeting the 16S rRNA gene of Peptostreptococcus magnus and used to attempt detection of Peptostreptococcus magnus DNA in subgingival plaque samples from adult periodontitis patients and pus aspirates from subjects with acute dento-alveolar abscesses. Although Peptostreptococcus magnus has not been found in the oral cavity using traditional, less-sensitive identification methods, PCR could be used to determine more accurately its true prevalence in the oral cavity.

\section{METHODS}

Bacterial culture and genomic DNA extraction. Peptostreptococcus magnus NCTC $11804^{\mathrm{T}}$ was cultured on fastidious anaerobe agar (Life Technologies) supplemented with defibrinated horse blood $(7 \cdot 5 \%, \mathrm{v} / \mathrm{v})$ and incubated at $37^{\circ} \mathrm{C}$ for $4-5$ days in an anaerobic chamber under an atmosphere of $85 \% \mathrm{~N}_{2}, 10 \% \mathrm{CO}_{2}$ and $5 \% \mathrm{H}_{2}$. Bacteria were harvested from the plates and genomic DNA was extracted using the Puregene DNA isolation kit (Novara Flowgen) in accordance with the manufacturer's instructions.

Sample details. Subgingival plaque was obtained from patients with untreated chronic inflammatory adult periodontitis who had been newly referred to Glasgow Dental Hospital. Criteria for inclusion in the study were the presence of at least three periodontal pockets with a depth of at least $5 \mathrm{~mm}$ and bleeding on probing, together with no history of antibiotic treatment during the preceding 6 months. In total, 39 subgingival plaque samples from 10 patients were analysed. The mean pocket depth of analysed samples was $7.0 \mathrm{~mm}$ (range 5-9 $\mathrm{mm}$ ) and the age range of the patients was $28-58$ years (mean $42 \cdot 0$ years). One pus sample from each of 60 subjects (age range 32-57 years; mean 43.9 years) was analysed.

Sample collection and preparation. Subgingival plaque samples were collected using a sterile curette into sterile tubes containing $0.5 \mathrm{ml}$ freshly prepared fastidious anaerobe broth (Bioconnections). Samples were mixed for $30 \mathrm{~s}$ and lysates were prepared by adding $3 \mu \mathrm{l}$

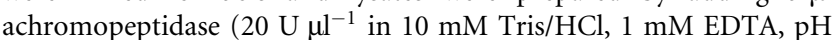
7.0) to $100 \mu \mathrm{l}$ of plaque sample. Samples were incubated at $56^{\circ} \mathrm{C}$ for $30 \mathrm{~min}$, boiled for $5 \mathrm{~min}$ and stored at $-70{ }^{\circ} \mathrm{C}$ until required.

Aliquots $(50 \mu \mathrm{l})$ of each pus sample were diluted 10- to 100-fold in PCR diluent (10 mM Tris/HCl, $\mathrm{pH} 8 \cdot 0,10 \mathrm{mM} \mathrm{NaCl}, 1 \mathrm{mM}$ EDTA). Next, $30 \mu \mathrm{l} 10 \% \mathrm{SDS}$ and $3 \mu \mathrm{l}$ proteinase $\mathrm{K}\left(10 \mathrm{mg} \mathrm{ml}^{-1}\right)$ were added to $300 \mu \mathrm{l}$ diluted pus and incubation was carried out at $55^{\circ} \mathrm{C}$ for $3 \mathrm{~h}$. Lysed samples were extracted twice with equal volumes of phenol/chloroform (1:1) and once with an equal volume of chloroform. DNA was precipitated by adding $0 \cdot 1$ vol. $3 \mathrm{M}$ sodium acetate, $\mathrm{pH} 5 \cdot 3$, and 2 vols $100 \%$ ethanol, mixing and incubation at $-70{ }^{\circ} \mathrm{C}$ for $30 \mathrm{~min}$. Precipitated DNA was recovered by centrifugation and the pellet was resuspended in $100 \mu \mathrm{l}$ sterile molecular-biology-grade water.

Selection of PCR primers. Primers targeting the 16S rRNA gene of Peptostreptococcus magnus were developed for use in the PCR assay. This was achieved by alignment of the $16 \mathrm{~S}$ rRNA gene sequences of Peptostreptococcus species and several other oral bacteria, using version 8 of the GCG sequence analysis package (Devereux et al., 1984). Primers with demonstrable $3^{\prime}$ sequence specificity for Peptostreptococcus magnus were selected from appropriate regions of the Peptostreptococcus magnus $16 \mathrm{~S}$ rRNA gene sequence. The primer sequences selected were Pmag-1 (5' -CGGGNTTTAGTAGACAGAAG-3'; base positions $60-79$; $\mathrm{N}=\mathrm{A}$, C, G or T) and Pmag-2 (5'-CAGTTTCCAATGCTTTACGG-3'; base positions 612-593). The expected size of the amplification product is $553 \mathrm{bp}$.

PCR. All PCRs were carried out in a total volume of $50 \mu \mathrm{l}$ and the PCR mixture was essentially as described previously (Riggio et al., 2000). Each PCR mixture comprised either $5 \mu$ lysed plaque sample/pus extract or $1 \mu \mathrm{l}$ bacterial genomic DNA and either 45 or $49 \mu \mathrm{l}$ reaction mixture containing $\mathrm{MgCl}_{2}$ at the optimum concentration of $1.5 \mathrm{mM}$. The PCR cycling conditions were an initial denaturation step of $94{ }^{\circ} \mathrm{C}$ for $5 \mathrm{~min}$ followed by 35 cycles of denaturation at $94^{\circ} \mathrm{C}$ for $1 \mathrm{~min}$, primer annealing at $60{ }^{\circ} \mathrm{C}$ for $1 \mathrm{~min}$ and extension at $72^{\circ} \mathrm{C}$ for $1 \mathrm{~min}$, with a final extension step at $72{ }^{\circ} \mathrm{C}$ for $10 \mathrm{~min}$.

Stringent anti-contamination procedures were employed when carrying out PCR, as described previously (Riggio et al., 2000). Negative and positive controls were included with each batch of samples analysed. The positive control was a standard PCR mixture containing $10 \mathrm{ng}$ Peptostreptococcus magnus genomic DNA instead of sample, whereas the negative control contained sterile water instead of sample. PCR products were visualized by electrophoresis on $2 \%$ agarose gels as described previously (Riggio et al., 2000).

Restriction endonuclease digestion of PCR products. PCR products were purified using the Wizard PCR purification kit (Promega) in accordance with the manufacturer's instructions. Aliquots containing $0.5 \mu \mathrm{g}$ purified DNA were digested in a total volume of $20 \mu \mathrm{l}$ with $5.0 \mathrm{U}$ RsaI (Promega) at $37^{\circ} \mathrm{C}$ for $3 \mathrm{~h}$. Restriction fragments generated were visualized by agarose gel electrophoresis.

Bacterial species used as PCR controls. Bacterial strains used as controls for PCR were from the Peptostreptococcus species Peptostreptococcus magnus (NCTC $11804^{\mathrm{T}}$, ATCC 29328 and three clinical isolates), Peptostreptococcus anaerobius ATCC $27337^{\mathrm{T}}$, Peptostreptococcus micros ATCC $33270^{\mathrm{T}}$, Peptostreptococcus asaccharolyticus NCTC $11461^{\mathrm{T}}$, Peptostreptococcus tetradius ATCC $35098^{\mathrm{T}}$, Peptostreptococcus productus NCTC $11829^{\mathrm{T}}$, Peptostreptococcus indolicus NCTC $11088^{\mathrm{T}}$ and Peptostreptococcus prevotii NCTC $11806^{\mathrm{T}}$. In addition, the following oral bacteria were also used as PCR controls: Prevotella intermedia ATCC $25611^{\mathrm{T}}$, Porphyromonas gingivalis ATCC $33277^{\mathrm{T}}$, Bacteroides forsythus ATCC $43037^{\mathrm{T}}$, Helicobacter pylori ATCC $43504^{\mathrm{T}}$, Actinobacillus actinomycetemcomitans ATCC $33384^{\mathrm{T}}$, Fusobacterium nucleatum ATCC $25586^{\mathrm{T}}$, Eikenella corrodens ATCC $23834^{\mathrm{T}}$, Streptococcus mutans ATCC $25175^{\mathrm{T}}$, Staphylococcus aureus ATCC $12600^{\mathrm{T}}$ and Actinomyces naeslundii ATCC $12104^{\mathrm{T}}$. With the exception of Peptostreptococcus magnus ATCC 29328 and the three clinical isolates of Peptostreptococcus magnus, all strains tested were type strains. 


\section{RESULTS}

\section{Sensitivity and specificity of the Peptostreptococcus magnus PCR assay}

Following 35 cycles of amplification, 50 Peptostreptococcus magnus cells were detectable by PCR (data not shown). The specificity of the PCR assay was confirmed by carrying out PCR under standard conditions using 10 ng genomic DNA from each of the bacterial species selected for use as controls. A PCR product of the expected size $(553 \mathrm{bp})$ was only obtained when DNA from each of the five Peptostreptococcus magnus strains tested was used as a template (data not shown), thereby confirming the specificity of the PCR assay for Peptostreptococcus magnus DNA.

\section{PCR detection of Peptostreptococcus magnus DNA in oral specimens}

The Peptostreptococcus magnus PCR assay was applied in the attempted detection of Peptostreptococcus magnus in oral specimens. Of 33 subgingival plaque samples from patients with adult periodontal disease that were analysed by PCR, 2 (6\%) contained Peptostreptococcus magnus DNA (Fig. 1). None of 60 pus aspirates from subjects with acute dentoalveolar abscesses was positive for the presence of Peptostreptococcus magnus DNA by PCR. Sample inhibition of PCR was discounted, since the spiking of subgingival plaque and pus samples with 1000 whole cells of Peptostreptococcus magnus yielded a PCR product of the expected size (data not shown).

In order to discount the possibility of cross-reactivity of the PCR primers with the human genome, PCR was also carried out using genomic DNA purified from primary oral epithelial cells as a template. No PCR product was obtained (data not shown), indicating the lack of cross-reactivity of these primers with human genomic DNA.

\section{Confirmation of PCR product specificity}

In order to confirm that successfully amplified products were derived from Peptostreptococcus magnus, PCR products were digested with the restriction endonuclease $R s a \mathrm{I}$, which gives a restriction profile unique to Peptostreptococcus magnus and therefore allows its distinction from other closely related Peptostreptococcus species. Digestion of PCR products obtained from Peptostreptococcus magnus gives DNA fragments with predicted sizes of 407, 80 and 66 bp (Fig. 2). All PCR products obtained from clinical specimens gave restriction patterns with RsaI that matched that expected for Peptostreptococcus magnus.

\section{DISCUSSION}

Peptostreptococcus magnus is one of the most common GPAC found in human clinical specimens and is regarded as being the most pathogenic. The purpose of this study was to develop a novel PCR assay for the specific detection of this organism and to apply this assay to its attempted detection in oral specimens. The PCR assay was demonstrated to be highly sensitive and specific for Peptostreptococcus magnus DNA. Conventional methods for identification of Peptostreptococcus magnus and indeed other members of the genus Peptostreptococcus are reliant upon bacterial culture coupled to biochemical identification of clinical isolates. Peptostrep-

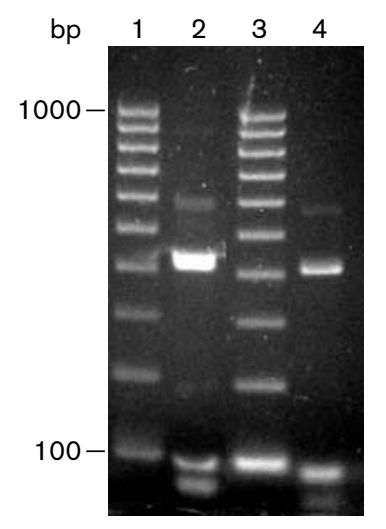

Fig. 2. Electrophoresis on a $2 \%$ agarose gel of 553 bp Peptostreptococcus magnus PCR products obtained from subgingival plaque samples following digestion with the restriction enzyme Rsal. Lanes: 1 and 3, 100 bp DNA ladder; 2 and 4, PCR products digested with Rsal. Confirmation of amplification of Peptostreptococcus magnus DNA was observed by the appearance of restriction fragments of 407,80 and $66 \mathrm{bp}$.

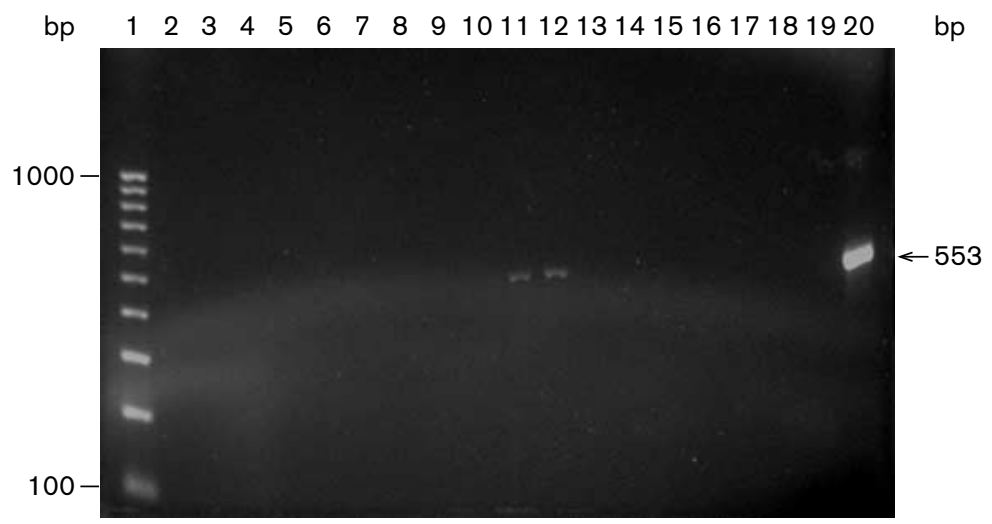

Fig. 1. Electrophoresis on a $2 \%$ agarose gel of PCR products obtained from analysis of subgingival plaque samples for Peptostreptococcus magnus DNA. Lanes: 1, 100 bp DNA ladder (fragment sizes 100-1000 bp in 100 bp increments); 2-18, subgingival plaque samples; 19, negative control; 20, positive control. A positive PCR result is indicated by the presence of a 553 bp product. 
tococcus magnus is commonly identified on the basis of colony morphology and Gram-staining characteristics, followed by biochemical analyses, such as carbohydrate fermentation tests, alkaline phosphatase production and detection of bacterially encoded proteolytic enzyme activities (Murdoch, 1998). The most useful of these tests for identification of Peptostreptococcus magnus are those that analyse bacterial proteolytic enzyme profiles using pre-formed kits such as RapID ANA II (Marler et al., 1991), Rapid ID32A (Ng et al., 1994) and ATB 32A (Murdoch \& Mitchelmore, 1991).

More recently, the use of GLC to detect the production of volatile fatty acid by-products of metabolism has been attempted as a means of identification of GPAC species (Murdoch \& Mitchelmore, 1991; Murdoch, 1998; Wilson et al., 2000). However, this method alone is not sufficient to identify Peptostreptococcus magnus, since Peptostreptococcus magnus, Peptostreptococcus micros and Peptostreptococcus heliotrinreducens all produce acetic acid alone as their terminal volatile fatty acid. It has been concluded that a combination of colony morphology, proteolytic enzyme profiles and Gram-stained cell morphology to assess cell size can be used to differentiate adequately between Peptostreptococcus magnus and Peptostreptococcus micros, thereby eradicating the need for GLC (Murdoch, 1998).

Whilst these methods have been of significant value, their usefulness is limited by the fact that the results obtained are often ambiguous, primarily because of the emergence of phenotypically atypical strains that may possess different biochemical characteristics. In addition, traditional identification methods are time-consuming, labour-intensive and expensive. PCR offers an alternative means of bacterial identification that overcomes these limitations. PCR is able to detect phenotypically divergent strains and is a rapid, highly specific and inexpensive method of bacterial identification.

An oligonucleotide $16 \mathrm{~S}$ rRNA probe has been described for Peptostreptococcus magnus, but was also shown to cross-react with Peptostreptococcus barnesae and Peptostreptococcus prevotii DNA (Conrads et al., 1997). Hence, this probe could not be used for reliable detection of Peptostreptococcus magnus in clinical samples. In the present study, we designed a pair of PCR primers based upon the 16S rRNA gene sequence of Peptostreptococcus magnus that were specific for the DNA of this organism. The PCR assay was used to attempt detection of Peptostreptococcus magnus DNA in subgingival plaque samples from adult periodontitis patients and in pus aspirates from subjects with acute dento-alveolar abscesses. Peptostreptococcus magnus DNA was detected in only $2(6 \%)$ of 33 subgingival plaque samples and in none of 60 pus aspirates analysed. This low incidence of Peptostreptococcus magnus in the oral cavity is perhaps not surprising, since previous studies using conventional culture-based methods have not identified Peptostreptococcus magnus in the oral cavity on any occasion. However, Peptostreptococcus anaerobius and, in particular, Peptostreptococcus micros have been identified in the oral cavity. Culture methods have found
Peptostreptococcus micros at elevated levels in a high proportion (58-91\%) of subgingival plaque samples from patients with periodontitis (Rams et al., 1992; van Dalen et al., 1998). The association of Peptostreptococcus anaerobius with the oral cavity is less striking, although it has been associated with gingivitis and periodontitis (Moore et al., 1987; Wade et al., 1992) and is one of the most frequently found species in the root canals of teeth with periapical periodontitis (Sundqvist, 1992). We have previously used PCR to detect Peptostreptococcus micros DNA in the subgingival plaque of $11(61 \%)$ of 18 adult periodontitis patients and in pus aspirates from acute dento-alveolar abscesses of $20(71 \%)$ of 28 subjects (Riggio et al., 2001). The evidence to date clearly suggests that Peptostreptococcus magnus is rarely found in the oral cavity and, to our knowledge, the present study is the first to use PCR to detect this organism, albeit at low prevalence, in the oral cavity.

The classification of members of the genus Peptostreptococcus is currently the subject of intense review. Several studies have suggested that members of the genus Peptostreptococcus should be removed from this genus and reclassified. On the basis of biochemical analysis and $16 \mathrm{~S}$ rRNA sequence data, it has been proposed that Peptostreptococcus magnus be reclassified in the new genus Finegoldia as Finegoldia magna and that Peptostreptococcus micros be reclassified in the new genus 'Micromonas' as 'Micromonas micros' (Murdoch \& Shah, 1999) (though the name 'Micromonas micros' is illegitimate because of the pre-existence of the fungal genus Micromonas). It has also been proposed that, on the basis of $16 \mathrm{~S}$ rRNA sequence data, Peptostreptococcus productus should be placed in the genus Ruminococcus (Ezaki et al., 1994). Three other new genera have been proposed for members of the genus Peptostreptococcus, namely Peptoniphilus (which includes Peptostreptococcus asaccharolyticus, Peptostreptococcus indolicus and three other species), Anaerococcus (which includes Peptostreptococcus prevotii and five other species) and Gallicola (which includes only Peptostreptococcus barnesae) (Ezaki et al., 2001). Peptostreptococcus anaerobius should be the only remaining member of the genus Peptostreptococcus (Murdoch et al., 2000).

In conclusion, we have developed and applied a novel PCR assay for the specific and direct detection of Peptostreptococcus magnus DNA in clinical specimens. This PCR assay was used to assess the prevalence of Peptostreptococcus magnus in subgingival plaque from adult periodontitis patients and in pus aspirates from subjects with acute dento-alveolar abscesses. Peptostreptococcus magnus was only detected at very low prevalence in subgingival plaque and was absent in the pus aspirates analysed, which suggests that this organism is not a putative pathogen in these lesions. The use of this PCR assay is advocated as a rapid, more-reliable alternative to conventional culture and biochemical methods for identification of Peptostreptococcus magnus in clinical specimens. 


\section{REFERENCES}

Bourgault, A. M., Rosenblatt, J. E. \& Fitzgerald, R. H. (1980). Peptococcus magnus: a significant human pathogen. Ann Intern Med 93, 244-248.

Brook, I. (1988). Recovery of anaerobic bacteria from clinical specimens in 12 years at two military hospitals. J Clin Microbiol 26, 1181-1188.

Brook, I. (1994). Peptostreptococcal infection in children. Scand J Infect Dis 26, 503-510.

Brown, M. A., Greene, J. N., Sandin, R. L. \& Vincent, A. L. (1994). Anaerobic meningitis caused by Peptostreptococcus magnus after head and neck surgery. Am J Med Sci 308, 184-185.

Conrads, G., Soffner, J., Pelz, K. \& Mutters, R. (1997). Taxonomic update and clinical significance of species within the genus Peptostreptococcus. Clin Infect Dis 25 (Suppl. 2), S94-S97.

Davies, U. M., Leak, A. M. \& Dave, J. (1988). Infection of a prosthetic knee joint with Peptostreptococcus magnus. Ann Rheumat Dis 47, 866-868.

Devereux, J., Haeberli, P. \& Smithies, O. (1984). A comprehensive set of sequence analysis programs for the VAX. Nucleic Acids Res 12, 387-395.

Edmiston, C. E., Jr, Walker, A. P., Krepel, C. J. \& Gohr, C. (1990). The nonpuerperal breast infection: aerobic and anaerobic microbial recovery from acute and chronic disease. J Infect Dis 162, 695-699.

Ezaki, T., Li, N., Hashimoto, Y., Miura, H. \& Yamamoto, H. (1994). $16 \mathrm{~S}$ ribosomal DNA sequences of anaerobic cocci and proposal of Ruminococcus hansenii comb. nov. and Ruminococcus productus comb. nov. Int J Syst Bacteriol 44, 130-136.

Ezaki, T., Kawamura, Y., Li, N., Li, Z.-Y., Zhao, L. \& Shu, S. (2001). Proposal of the genera Anaerococcus gen. nov., Peptoniphilus gen. nov. and Gallicola gen. nov. for members of the genus Peptostreptococcus. Int J Syst Evol Microbiol 51, 1521-1528.

Fitzgerald, R. H., Jr, Rosenblatt, J. E., Tenney, J. H. \& Bourgault, A. M. (1982). Anaerobic septic arthritis. Clin Orthop 164, 141-148.

Johnson, S., Lebahn, F., Peterson, L. R. \& Gerding, D. N. (1995). Use of an anaerobic collection and transport swab device to recover anaerobic bacteria from infected foot ulcers in diabetics. Clin Infect Dis 20 (Suppl. 2), S289-S290.

Kamma, J. J., Diamanti-Kipioti, A., Nakou, M. \& Mitsis, F. J. (2000). Profile of subgingival microbiota in children with primary dentition. J Periodontal Res 35, 33-41.

Marler, L. M., Siders, J. A., Wolters, L. C., Pettigrew, Y., Skitt, B. L. \& Allen, S. D. (1991). Evaluation of the new RapID-ANA II system for the identification of clinical anaerobic isolates. J Clin Microbiol 29, 874-878.

Moore, L. V. H., Moore, W. E. C., Cato, E. P., Smibert, R. M., Burmeister, J. A., Best, A. M. \& Ranney, R. R. (1987). Bacteriology of human gingivitis. J Dent Res 66, 989-995.
Murdoch, D. A. (1998). Gram-positive anaerobic cocci. Clin Microbiol Rev 11, 81-120.

Murdoch, D. A. \& Mitchelmore, I. J. (1991). The laboratory identification of gram-positive anaerobic cocci. J Med Microbiol 34, 295-308.

Murdoch, D. A. \& Shah, H. N. (1999). Reclassification of Peptostreptococcus magnus (Prevot 1933) Holdeman and Moore 1972 as Finegoldia magna comb. nov. and Peptostreptococcus micros (Prevot 1933) Smith 1957 as Micromonas micros comb. nov. Anaerobe 5, 555-559.

Murdoch, D. A., Mitchelmore, I. J. \& Tabaqchali, S. (1994). The clinical importance of gram-positive anaerobic cocci isolated at St Bartholomew's Hospital, London, in 1987. J Med Microbiol 41, 36-44.

Murdoch, D. A., Shah, H. N., Gharbia, S. E. \& Rajendram, D. (2000). Proposal to restrict the genus Peptostreptococcus (Kluyver \& van Niel 1936) to Peptostreptococcus anaerobius. Anaerobe 6, 257-260.

Ng, J., Ng, L. K., Chow, A. W. \& Dillon, J. A. R. (1994). Identification of five Peptostreptococcus species isolated predominantly from the female genital tract by using the rapid ID32A system. J Clin Microbiol 32, 1302-1307.

Panagou, P., Papandreou, L. \& Bouros, D. (1991). Severe anaerobic necrotizing pneumonia complicated by pyopneumothorax and anaerobic monoarthritis due to Peptostreptococcus magnus. Respiration 58, 223-225.

Rams, T. E., Feik, D., Listgarten, M. A. \& Slots, J. (1992). Peptostreptococcus micros in human periodontitis. Oral Microbiol Immunol 7, 1-6.

Riggio, M. P., Lennon, A. \& Wray, D. (2000). Detection of Helicobacter pylori DNA in recurrent aphthous stomatitis tissue by PCR. J Oral Pathol Med 29, 507-513.

Riggio, M. P., Lennon, A. \& Smith, A. (2001). Detection of Peptostreptococcus micros DNA in clinical samples by PCR. J Med Microbiol 50, 249-254.

Sundqvist, G. (1992). Associations between microbial species in dental root canal infections. Oral Microbiol Immunol 7, 257-262.

van Dalen, P. J., van Winkelhoff, A. J. \& van Steenbergen, T. J. M. (1998). Prevalence of Peptostreptococcus micros morphotypes in patients with adult periodontitis. Oral Microbiol Immunol 13, 62-64.

van der Vorm, E. R., Dondorp, A. M., van Ketel, R. J. \& Dankert, J. (2000). Apparent culture-negative prosthetic valve endocarditis caused by Peptostreptococcus magnus. J Clin Microbiol 38, 4640-4642.

Wade, W. G., Moran, J., Morgan, J. R., Newcombe, R. \& Addy, M. (1992). The effects of antimicrobial acrylic strips on the subgingival microflora in chronic periodontitis. J Clin Periodontol 19, 127-134.

Wilson, M. J., Hall, V., Brazier, J. \& Lewis, M. A. O. (2000). Evaluation of a phenotypic scheme for the identification of the 'butyrate-producing' Peptostreptococcus species. J Med Microbiol 49, 747-751. 